\title{
Marine Diesel Engine Transient Operation with Reduced Smoke Emissions*
}

\author{
Livanos George, Kanellopoulou Evina, Kyrtatos Nikolaos **
}

This paper presents the simulation of operation of a turbocharged medium-speed marine diesel engine, incorporating two prototype modifications to counteract fuel-air mismatch during transient loading - injection of high pressure air on the compressor impeller and variable path exhaust manifold allowing pulse or constant pressure turbocharging. The simulation work was performed using the MOTHER code, an in-house developed thermodynamic code, applied to the MAN B\&W 5L16/24 test engine, installed in the Laboratory of Marine Engineering NTUA. For typical transient engine loading profiles, obtained from ship-board measurements, the simulation results clearly show the improved response of the turbocharger compressor. The simulation results were used in the design of related experiments, with the prototype components installed on a test engine.

\section{Introduction}

The marine diesel engine, which accounts today for $98 \%$ of ship propulsion, has inherently low emissions of carbon monoxide and unburned hydrocarbons. Emissions from marine diesel engines account for about $4.5 \%$ of total mobile source NOx emissions and about $1 \%$ of particulate matter emissions. Despite the relatively low contribution of marine power plants to global emission levels, the contribution of ships to emissions in harbors and near coastal areas is significantly higher [1].

Problems of smoke emissions can affect ship propulsion engines when they undergo rapid load changes, during engine acceleration or constant engine speed/variable load operation. When the turbocharged diesel engine is undergoing a transient load increase, the required fuelling increase cannot be matched initially with the required air, due to the turbocharger lag in response.

The problem of the engine fuel-air mismatch and resulting smoke emissions, during fast transient engine loadings, was studied in detail in the project "Smoke Emissions Reduction in Marine Engines" (SMOKERMEN) funded by the European Union.

This paper presents the results of the simulation and performance prediction of a medium speed marine diesel engine, incorporating the following two prototype modifications to counteract fuel-air mismatch during transient loading: a) injection of high pressure air onto the turbocharger compressor impeller and b) variable path exhaust manifold, allowing pulse or constant pressure turbocharging. Typical transient engine loading profiles for propulsion engines and onboard generator were obtained in the framework of project SMOKERMEN. These were adapted and used in the test engine simulations, and the effects of using the two prototype modifications on the turbocharger and engine performance were investigated.

The simulation results were used for the design of experiments, to optimize these prototype components installed on a test-bed engine. 


\section{Engine Setup}

The prototype components for the compressor air injection and pulse turbocharging were to be installed on a MAN B\&W 5L16/24 test engine coupled to an AEG electric brake in the laboratory of Marine Engineering of National Technical University of Athens. Thus, all simulation work in this study was performed for this engine [2], [3].

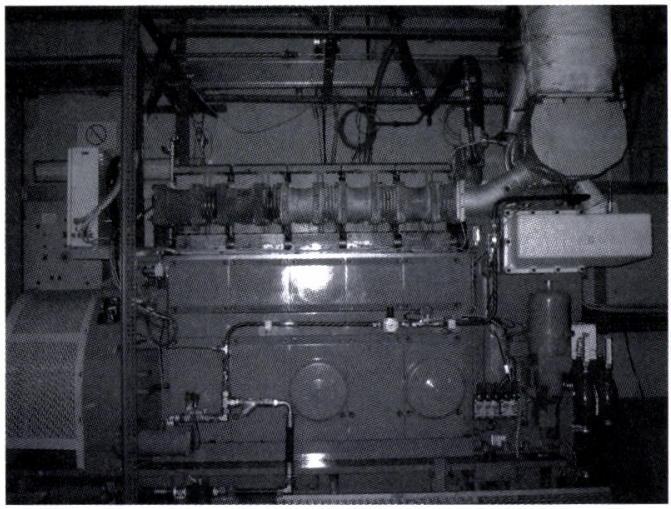

(a)

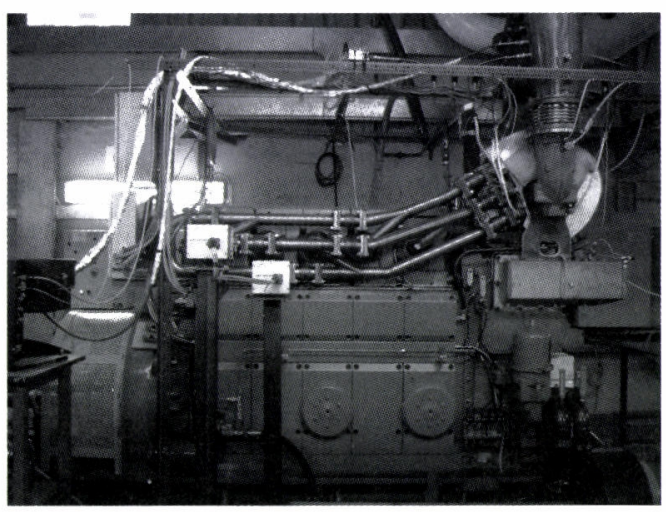

(b)

Fig. 1: The MAN B\&W L1624 test engine

(a) Initial configuration

(b) Variable path exhaust manifold system configuration

For the present study a new turbocharger (ABB TPS48EX) was to be retrofitted on the engine (Figure 1a).

For the experimental investigation of engine performance with high pressure air injection on the compressor impeller, a high pressure air injection system was to be installed. The high pressure air injection system allowed the supply of compressed air from bottles through orifices onto the compressor impeller blades.

For the pulse turbocharging application, the existing conventional exhaust manifold was to be replaced by a variable path exhaust manifold, consisting of three pipes interconnected with two butterfly valves. A 3 entry turbine casing was to replace the existing single entry one. When the butterfly valves are fully opened, this turbocharger system operation is converted from pulse to constant pressure type (Figurelb).

\section{Engine Simulation Code}

The thermodynamic engine simulation code MOTHER (MOtor THERmodynamics) is the main simulation tool used in the Laboratory of Marine Engineering (NTUA), for the performance prediction of engines under steady state, as well as dynamic (transient) conditions.

MOTHER is a general purpose engine performance prediction program based on the thermodynamic control volume principle. Its underlying methodology allows the simulation of the operation and performance of the complete engine power-train system. The model is also capable of predicting transient response characteristics and behavior of the various components under dynamic control schedules [4, 5, 6]. A detailed description of the code working principles and capabilities can be found in [4].

Figure 2 presents the engine model after the replacement of the single exhaust manifold (constant pressure turbocharging system) with the system of the interconnected exhaust pipes (variable path pulse turbocharging system).

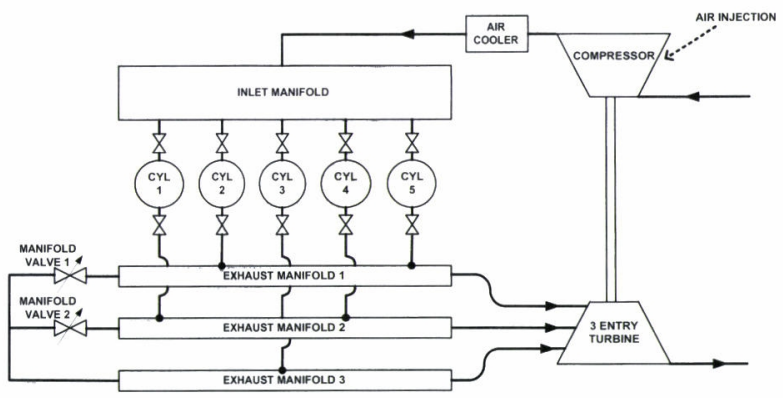

Fig. 2 The MAN B\&W L1624 engine setup used in the simulations

\section{High Pressure Air Injection System Modeling}

When a large load is suddenly applied to a turbocharged engine, the air-fuel ratio falls quickly to a 
very low value and combustion becomes poor; although more fuel can be rapidly injected into the cylinders, the turbocharger has a slow response providing a corresponding increase in air for combustion. Improvements can thus be achieved both by controlling the fuel flow and by accelerating the turbocharger at the onset of the load with external means. One method of accelerating the turbocharger is to inject air onto the impeller of the compressor, with the additional advantage that this amount of air is also available for combustion.

To simulate the effect of the injected air to the engine response during transient loading the compressor air injection model of Ledger-Benson-Furukawa [7] was used. According to this model the influence of air injection on the compressor characteristics is an increase to the delivery pressure ratio and flow rate, as well as a reduction to the necessary torque to drive the compressor for the same delivery rate. Thus, the constant speed curves in the compressor map (derived from steady state operation) appear to be shifted in the direction of increased pressure ratio and increased flow parameter. The values of pressure increase $\Delta \mathrm{p}$, volumetric flow increase $\Delta \mathrm{V}$ and impeller torque reduction $\triangle \mathrm{M}$ were obtained from $\mathrm{ABB}$, for the TPS 40 compressor, which was to be installed on the MAN B\&W 5L16/24 engine of NTUA/LME test-bed.

The above described air injection model was incorporated in MOTHER code as follows:

- The additional impeller torque provided by the air injection was simulated as an external load applied on the turbocharger shaft. Thus, the compressor is driven both by the turbine torque and the additional air injection torque.

- The shift of the compressor map constant speed curves, due to air injection, was simulated as a time dependent compressor map shifting, towards higher pressure ratios and flow rates. Thus the compressor operating point moves towards higher pressure ratios and flow rates for a certain $\mathrm{T} / \mathrm{C}$ speed.

\section{Variable Path Exhaust Manifold System Modeling}

Another method for preventing the lambda drop during a sudden load increase is the use of a pulse turbocharging system. Lambda $(\lambda)$ is defined as the actual air fuel/ratio divided by the chemically correct (stoichiometric) air/fuel ratio.

The variable path exhaust manifold system allows to fully exploit the potential of pulse turbocharging for part load and acceleration operation and to revert to a constant pressure system for high load steady state operation. When the system valves are closed, the low volume system pipes give high pressure pulses and cause very efficient transmission of the blow down energy to the turbine. In high load operation, the pipes are interconnected (i.e. valves are opened) so as to reduce the amplitude of the pressure pulsation.

The variable path exhaust manifold system was incorporated in the MOTHER code as follows:

- The three pipes of the turbocharging system were simulated as three plenums with constant volumes. Each plenum volume was equal to the corresponding pipe volume.

- The two hot gas butterfly valves connecting the three pipes were simulated as flow controllers (valves).

- The 3-entry turbine was simulated as three smaller identical turbines connected to the compressor via the same shaft. The efficiency of each turbine was taken equal to the efficiency of the actual turbine, operating under steady state conditions, multiplied by a pulse factor. The pulse factor, which incorporates the effect of exhaust gas pulses on the turbine efficiency for two operating modes (two valves open and two valves closed), was provided by the turbocharger manufacturer (ABB).

\section{Simulation Results}

The objective of this section is to present the simulation work performed with the above described models, for the investigation of the engine transient response, using air injection on the compressor impeller or variable path exhaust manifold system. The results from the simulation work were used in the design of experiments, conducted by the Laboratory of Marine Engineering, with the two prototype systems installed on the test engine.

\subsection{Steady State Operation}

Before the engine transient response investigation, several steady state runs at $25 \%, 50 \%, 75 \%$ and $100 \%$ engine load at $1200 \mathrm{rpm}$ were performed, in order to calibrate the various sub-models on the simulation code. The predicted results were found to be in good 
agreement with the values measured on the laboratory's test-bed.

\subsection{Transient Operation}

After the initial steady state runs, a large series of transient runs were performed, based on measured typical loading profiles. Several loading profiles were extracted from processing a series of onboard measurements conducted in the framework of the project "SMOKERMEN" for a variety of ships and engines. The loading profiles were adapted and grouped in two categories: transient loadings with constant speed (generator duty) and transient loadings with variable speed (propeller load).

\subsubsection{Transient Operation with air injection on the} compressor impeller

After the determination of loading profiles applied on the test engine, a large series of transient runs, were performed, with and without air injection onto the compressor impeller, for constant speed (generator duty) and variable speed (propeller load) operation. Three cases of engine transient operation are presented here:

- Case 1: Linear engine load increase from $25 \%$ to $50 \%$ in 1 second at $1200 \mathrm{rpm}$ with compressor air injection system ( 3 and 5 bar air injection pressure), activated for 4 seconds.

- Case 2: Linear engine load increase from $25 \%$ to $50 \%$ in 1 second at $1200 \mathrm{rpm}$ with compressor air injection system (3 and 5 bar injection pressure) activated for 1.5 second.

- $\quad$ Case 3: Engine acceleration from $880 \mathrm{rpm}$ to 1200 rpm in 20 seconds, following the propeller law, with compressor air injection application for the whole duration of the transient loading.

In the first case, the engine response during linear load increase from $25 \%$ to $50 \%$ load, at $1200 \mathrm{rpm}$, with compressor air injection of 3 and 5 bar pressure, was examined. It was assumed that air injection is activated concurrently with load increase and lasts for 4 seconds. Figures 3 and 4 present the predicted power, engine speed, T/C speed, lambda and NOx concentration with air injection ( 5 and 3 bar) and without air injection. It can be seen that air injection helps the engine stabilize more quickly. The engine speed drop and power overshoot are smaller in magnitude and duration.

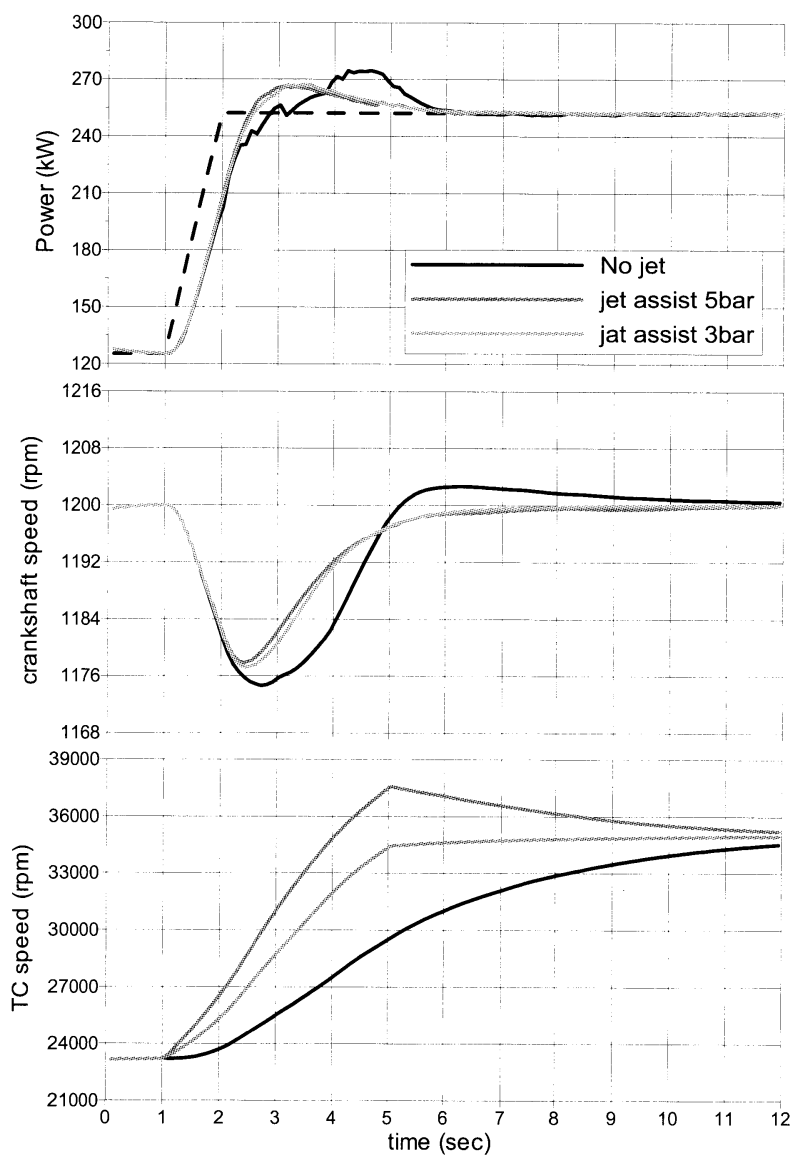

Fig. 3 Simulation results for linear engine load increase from $25 \%$ to $50 \%$ at $1200 \mathrm{rpm}$ with air injection ( 3 and 5 bar pressure, $4 \mathrm{~s}$ duration)

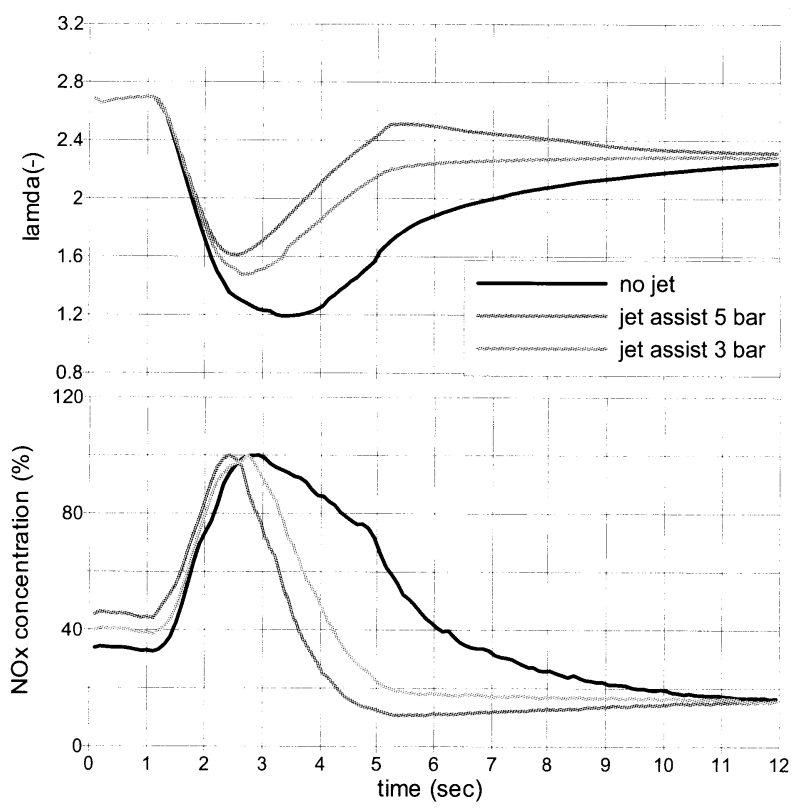

Fig. 4 Simulation results for linear engine load increase from $25 \%$ to $50 \%$ at $1200 \mathrm{rpm}$ with air injection ( 3 and 5 bar pressure, $4 \mathrm{~s}$ duration) 
Although the NOx concentration reaches the same maximum value with and without air injection, in the second case NOx concentration quickly falls to steady state limits, since the compressor reaches faster the required operational point to meet the increased fuelling conditions. The effect of air injection pressure on the engine response is not important, since for both air injection pressures ( 3 and 5 bar) the engine response is similar.

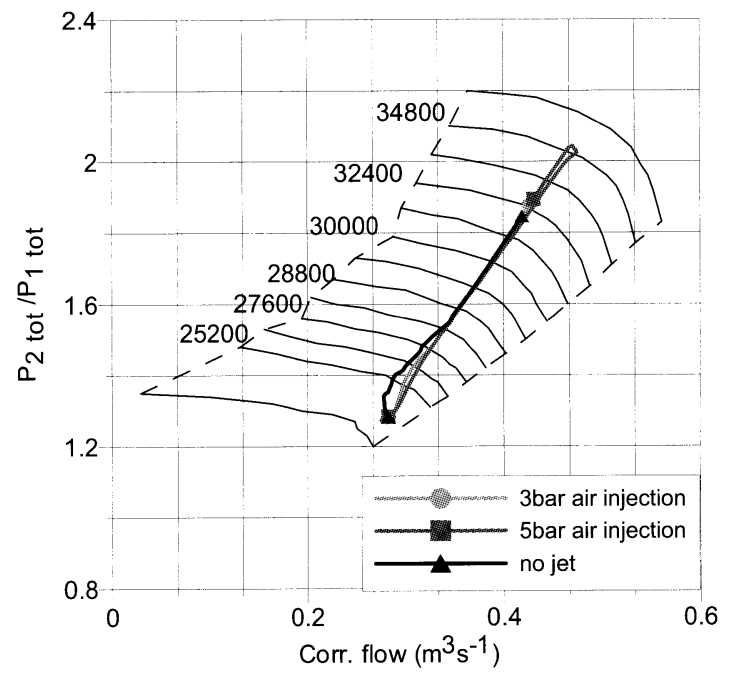

Fig. 5 Compressor operating point trajectory for linear engine load increase from $25 \%$ to $50 \%$ at 1200 rpm with air injection ( 3 and 5 bar pressure, $1.5 \mathrm{~s}$ duration)

An explanation of the above mentioned positive effects of the compressor air injection can be drawn from the turbocharger response presented in Figure 5, with and without air injection, during the transient loading. As can be seen, the air injection greatly affects the turbocharger speed rise. As air injection pressure increases the compressor reacts faster to load increase and the engine is adequately charged with air, so that high fuel-air ratios and poor combustion is prevented. Thus, regarding the NOx concentration profile mentioned in the previous paragraph, the sudden NOx increase is due to the high fuel-air ratio initially developed, and the faster NOx reduction in case of air injection is due to the faster fuel-air ratio reduction (faster compressor acceleration - more available air for combustion - lower in-cylinder temperature - lower NOx emissions). It can be also seen that for air injection pressure of 5bar, an undesired overshoot of the turbocharger speed is observed. Thus, it can be concluded that an air injection pressure between 3 and 5 bar (e.g. 4 bar) would be more suitable for such transient loadings. This result was taken into account in the design of experiments and most of experimental tests were performed with air injection pressures not exceeding the operation limit of 4 bars.

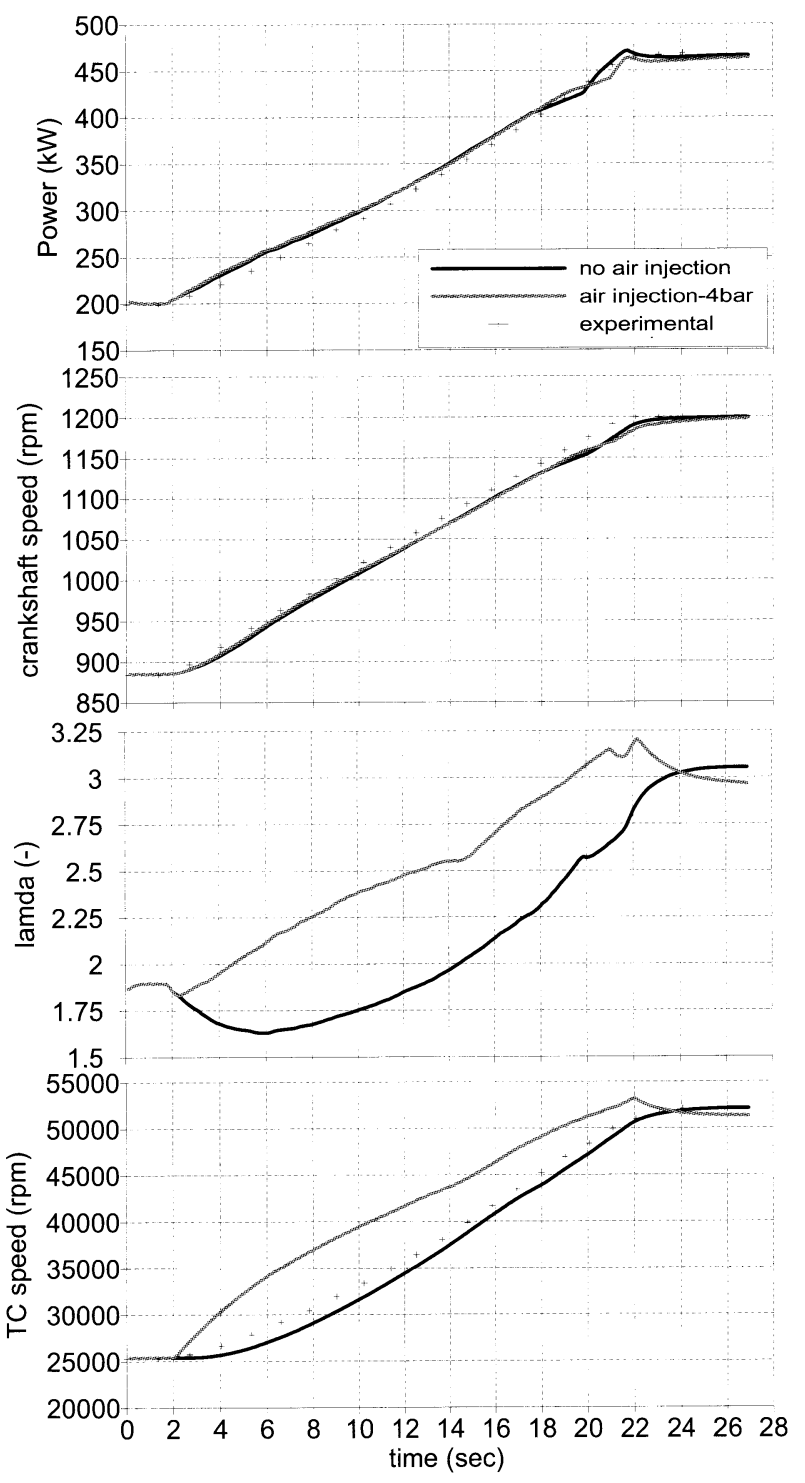

Fig. 6 Simulation and experimental results of engine response with and without air injection (4 bar pressure, 20s duration) during propeller law acceleration from $880 \mathrm{rpm}$ to $1200 \mathrm{rpm}$

In the second case, an air injection with shorter duration (1.5 seconds) was investigated for the same load rate increase. It was observed that, although the predicted engine power overshoot and speed drop is almost the same as in the previous case, the NOx concentration needs more time to settle down to steady state limits, 
since the compressor needs more time to reach the new steady state operating point due to the shorter assistant air injection action. Thus, it was decided that air injection duration should be in the neighborhood of 4 seconds for avoiding air-fuel mismatch.

In the third case, the transient engine operation following the propeller law was simulated. In this case the engine accelerates from $880 \mathrm{rpm}$ to $1200 \mathrm{rpm}$, following the propeller law. Figure 6 presents a typical set of predicted results including brake power, engine speed, turbocharger speed and lambda ratio. As can be seen, the compressor accelerates slowly, no T/C speed overshoot is observed and the predicted results are in full agreement with the measured results from LME/NTUA test bed.

The engine response in the above mentioned case was also examined under the action of air injection onto the compressor impeller. In this transient simulation run the air injection was activated with load increase for the whole transient duration. The air injection pressure was set to 4 bar. The predicted engine response, with and without air injection, is comparatively presented in Figure 6. As can be drawn from this figure, the engine torque and speed are the same either the air injection system is activated or not, but on the other hand the turbocharger accelerates faster with the air injection, preventing poor combustion (lambda drop) and smoke emissions

It is concluded from the results of this simulation run, that air injection system should be active during the overall engine acceleration period to help compressor to accelerate faster and supply more air to engine, which in turn meets faster new fuelling conditions imposed by governor action, and less smoke emissions are produced. On the other hand the additional air supply during the transient loading, reduces the maximum in-cylinder temperature and consequently NOx emissions.

\subsubsection{Transient Operation with Variable Path}

Exhaust Manifold System

The MAN B\&W 5L16/24 transient operation, with the variable path pulse turbocharging system, was also investigated as an alternative system for reducing smoke emissions. Engine transient operation under constant (Gen-set) and variable speed (propeller law) was simulated, for the two operational modes of turbocharging system (i.e system valves open and closed), under several scenarios. The following cases were studied in detail:

- Case 1: Engine acceleration of 20 seconds duration, from $880 \mathrm{rpm}$ to $1200 \mathrm{rpm}$, following propeller law, with the turbocharging system valves initially fully open and fully closed for 10 and 20 seconds after the load application.

- $\quad$ Case 2: linear engine load increase from $25 \%$ to $50 \%$ in 1 second, at $1200 \mathrm{rpm}$, with turbocharging system valves opened and closed for 1, 2 and 3 seconds after the load application (running time $4 \mathrm{~s}$ ).

In case 1 , the turbocharging system valves were fully closed for the first 10 and 20 seconds of the transient loading, and then fully open for the rest of the loading. Despite the lower turbine efficiencies due to exhaust gas pulses, the turbine delivered power is higher due to the increased pressure field developed upstream of the turbine. The increased turbine power urges the compressor to operate at higher rotational speeds and pressure ratios and thus more air is available to engine for combustion and less smoke emissions are produced (Figure 7).

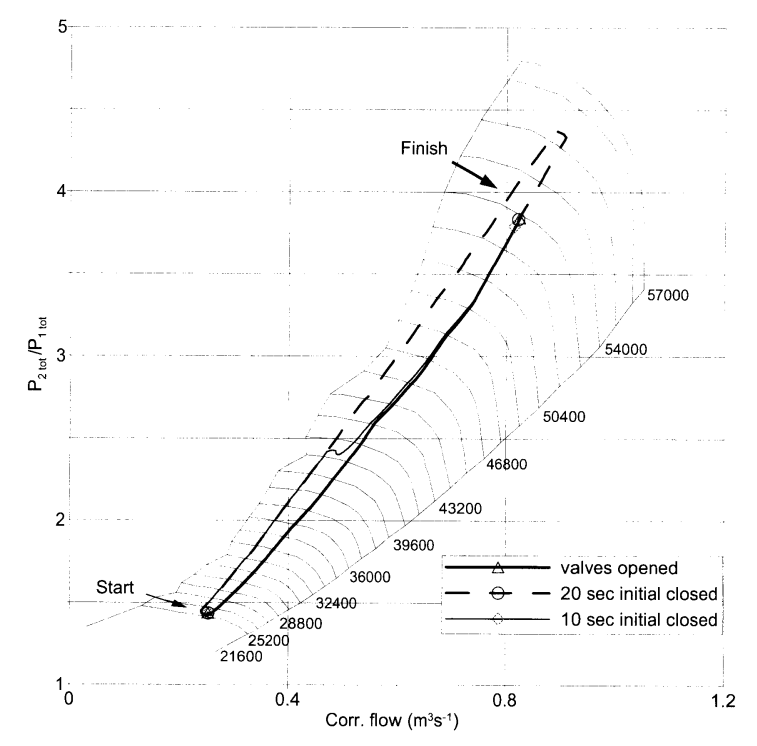

Fig. 7 Compressor operating point trajectory during propeller law acceleration from $40 \%$ to $100 \%$ load with different close-timing for the exhaust manifold valves

In case 2, the engine response during a step transient loading (from $25 \%$ to $50 \%$ load within 1 second), with the turbocharging system valves fully closed for 1,2 and 3 seconds, was examined for the determination of the optimum system valves timing. Typical predicted 
results including the lambda ratio, the engine torque, the engine speed and the turbocharger speed are presented in Figure 8.

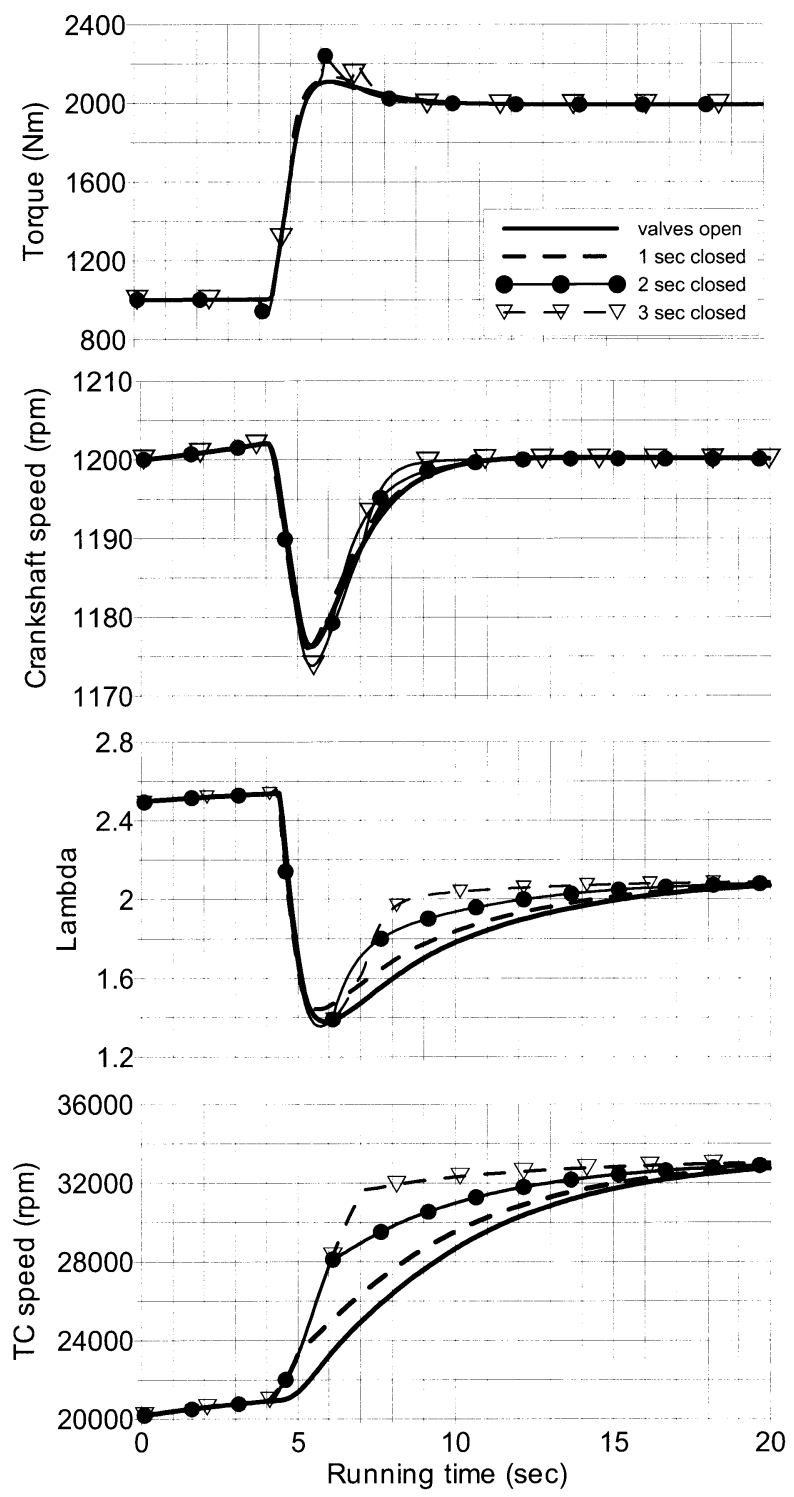

Fig. 8 Simulation results for linear engine load increase from $25 \%$ to $50 \%$ at $1200 \mathrm{rpm}$ with different close-timing for the exhaust manifold valves

The favourable engine response when the valves are closed for 3 seconds after the load application is evident: the lambda ratio returns to acceptable levels after 5 seconds (contrary to 15 seconds needed in the case of open valves). A slightly larger speed drop (and a corresponding rack position overshoot) is observed in the case of 3 seconds closed valves. The pressure in exhaust plenums is rapidly developed and the compressor mass flow rate initially decreases in the case of closed valves. After about 0.5 seconds the turbine delivers additional power (due to the increased pressure developed in the turbine inlet) and the compressor accelerates towards higher pressure ratios and flow rates.

\section{Conclusions}

The objective of this paper was the presentation of results of simulation and performance prediction of a medium speed marine diesel engine, operating under transient loading conditions (at constant speed or along a propeller curve). To reduce engine smoke emissions during transient loading, due to the turbocharger lag in response, air injection onto the compressor impeller and pulse turbocharging system with variable path exhaust manifold were investigated. From the simulation results analysis comes out that both methods contribute in preventing the fuel-air mismatch and poor combustion. More air is readily available for combustion, due to the direct action (air injection onto compressor impeller) or indirect action (pulse energy absorption from the turbine) of these techniques.

The simulation data obtained for various scenarios for the air injection application and manifold valve opening-closing, as well as for various injected air pressure values, provided an indication of the engine performance and were used for the design of experiments with the prototype components installed on the test engine.

\section{Acknowledgements}

The work reported in this paper was partly funded by the European Commission through the project SMOKERMEN (Smoke Emission Reduction in Marine Engines) Contract No (GRD2-2001-50009) with E.C. project officer Mr. F. Sgarbi.

The authors wish to thank all the partners of the "SMOKERMEN" project, who provided valuable technical information used in the simulation. Special thanks to Dr. E. Codan and Dr. I. Vlaskos of ABB Turbo Systems AG for information on air injection on the compressor wheel and pulse effect on the turbocharger turbine, and Mr. R. Boom of Woodward Governor B.V. for controller data. 


\section{References}

[1] Isensee, J., Bertram, V. and Keil, H., Energy Efficiency and Air Pollution: A comparison of Ships and Other Vehicles, Proceedings of the Fourth International Conference on Fast Sea Transportation (FAST 97), 1997.

[2] Kyrtatos, N.P., Ioannides, I.P, Pavlidis, V., Ventouris, K., Raptis, D., The New Laboratory Facility (MARTHA) for Marine Propulsion Research \& Development, 23rd CIMAC Congress, Hamburg, May 7-10, 2001.

[3] MAN B\&W, Project Guide for Marine Genset L16/24, Ed. 4, January 1999.

[4] Kyrtatos, N.P., Tzanos, E.I., Papadopoulos, C.I., "Diesel Engine Control Optimisation for Transient Operation with Lean/Rich Switches". Int. J. Engine Research, Vol. 4, No 3, pp. 219-231, 2003.

[5] Kyrtatos, N.P., and Koumbarelis, I., "Performance Prediction of Next-Generation Slow Speed Diesel Engines during Ship Manoeuvers", Trans ImarE, Vol. 106, Part 1, pp $1-26,1994$.

[6] Kyrtatos, N.P., Theodossopoulos, P., Theotokatos, G., Xiros, N. "Simulation of the Overall Ship Propulsion Plant for Performance Prediction \& Control". MarPower '99 Conference, Newcastle-upon-Tyne, March 25-26, 1999.

[7] Ledger, J.D., Benson, R.S., Furukawa, H., Performance Characteristics of a Centrifugal Compressor with Air Injection, Proceedings of I.Mech.E, Vol 187 35/73.

Authors

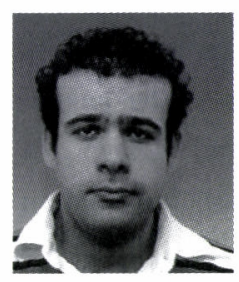

-Livanos, George

-Born in 1979

-Research Engineer

- graduated from National Technical

University of Athens

-Extreme Parameter Engines

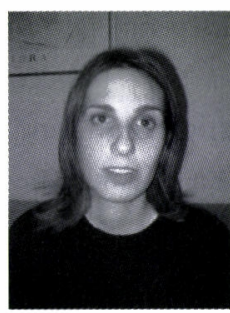

-Kanellopoulou, Evina

-Born in 1978

- Research Engineer

-graduated from National Technical University of Athens

-Thermodynamics

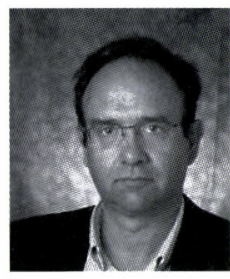

-Kyrtatos, Nikolaos

-Born in 1954

-Professor of Marine Engineering, National Technical University of Athens

- graduated from University of London -Marine Engineering 